Aletria, Belo Horizonte, v. 30, n. 1, p. 119-134, 2020

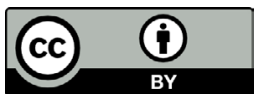

\title{
Uma literatura nos trópicos: notas ao pé da página Uma literatura nos trópicos: Footnotes
}

\author{
Eneida Leal Cunha \\ Pontifícia Universidade Católica do Rio de Janeiro (PUC-Rio), Rio de Janeiro, \\ Rio de Janeiro / Brasil \\ eneida.l.cunha@gmail.com \\ http://orcid.org/0000-0001-5697-6799
}

Resumo: Como "notas ao pé da página", o artigo retorna a Uma literatura nos trópicos e a seu mais célebre ensaio, "O entre-lugar do discurso latino-americano", para articulálos a uma sequência de ensaios posteriores publicados pelo autor Silviano Santiago, nos quais se reiteram e se desdobram os ímpetos do gesto crítico inaugural, desconstrutor, intempestivo e extemporâneo. Exploram-se, portanto, em trabalhos escritos entre 1972 e 2000, as operações de confronto com linearidade do argumento histórico, as leituras a contrapelo, as recuperações no arquivo colonial e a exploração dos nexos recalcados que sustentam e legitimam, no Brasil, hierarquias, violências, exclusões, racismos e a obliteração da palavra do Outro.

Palavras-chave: Silviano Santiago; Uma literatura nos trópicos; crítica contemporânea; crítica pós-colonial.

Abstract: As footnotes, we return to Uma literatura nos trópicos (A Literature in the Tropics) and to its most notable essay, "O entre-lugar do discurso latino-americano" (The In-Between Space of the Latin American Discourse). We connect these works to a series of later essays by Silviano Santiago, in which he reiterates and develops the original, deconstructive and untimely critical gesture. Hence, we explore, in writings published between 1972 and 2000, how the author contests the linearity of historical argument, reads against the grain, returns to the colonial archive and explores the repressed nexus of connections, in Brazil, that sustains and legitimates hierarchies, violence, exclusion, racisms and the erasure of the word of the Other.

Keywords: Silviano Santiago; Uma literatura nos trópicos; contemporary criticismo; postcolonial criticism. 
[...] as margens de um livro jamais são nítidas nem rigorosamente determinadas: além do título, das primeiras linhas e do ponto final, além de sua configuração interna e da forma que lhe dá autonomia, ele [o livro] está preso em um sistema de remissões a outros livros, outros textos, outras frases: nó em uma rede.

Michel Foucault (1969)

Este retorno ao livro de Silviano Santiago dá sequência a algumas entradas anteriores em sua obra crítica, em especial a incursões recentes na coletânea de 1978, como o artigo publicado no Suplemento Pernambuco de maio de 2018, o debate realizado na PUC Rio naquele mesmo mês, a curadoria da vídeo-homenagem que fizemos para a ocasião - 40 anos de Uma literatura nos trópicos [entre afetos] - e o seminário itinerante promovido por pesquisadores de diferentes áreas de conhecimento e instituições (UFRJ, UNICAMP e UFMG) no segundo semestre de 2018. Dessa comunidade de textos deriva o título (notas ao pé da página) e a decisão de aqui suplementar leituras anteriores, minhas, do trabalho seminal de Santiago.

Retomo a epígrafe que usei para a vídeo-homenagem, um pequeno trecho do primeiro capítulo da Arqueologia do Saber, localizado poucas páginas adiante do recorte feito pelo próprio Silviano Santiago no mesmo livro de Michel Foucault, há mais de 40 anos, para introduzir o ensaio "O entre lugar do discurso latino-americano", epígrafe sua que preparava o leitor da coletânea para as inadiáveis tarefas da crítica contemporânea contra as formas da semelhança e da unidade. ${ }^{1}$

Como Michel Foucault em 1969 na França, Santiago, nos escritos do início dos anos de 1970, integra, a seu modo e do seu lugar periférico, as vanguardas teóricas da segunda metade do século XX: em significativa sincronia com o pensador francês, o crítico brasileiro também escreve para se contrapor àquelas "disciplinas tão incertas de suas fronteiras e tão indecisas de seu conteúdo como a história das ideias, do pensamento, ou do conhecimento" (FOUCAULT, 1978, p. 23); ou às linearidades constituídas pela historiografia da cultura, das artes e da literatura, acrescento eu; escreve para confrontar "o jogo de noções

\footnotetext{
1 "Antes de mais nada, tarefas negativas. É preciso libertar-se de todo um jogo de noções que estão ligadas ao postulado da continuidade [...]" (FOUCAULT, 1978, p. 23).
} 
que diversificam, cada uma à sua maneira, o tema da continuidade" (FOUCAULT, 1978, p. 23). Os alvos desse trabalho de desconstrução são as noções de tradição (e sua correlata, a ruptura), de influência, de evolução e de mentalidade, espírito ou estilo de época, que então prevaleciam nas estratégias analíticas e no referencial bibliográfico da maioria dos seus críticos contemporâneas e, por consequência, nas bibliografias das disciplinas dos cursos de Letras nas universidades.

Além de problematizar e desautorizar tais noções, Foucault, no mesmo segmento da Arqueologia do Saber, nos propõe que, "sobretudo", é preciso pôr em suspeição e em suspensão as duas unidades mais imediatas do campo das Ciências Humanas: o livro e a obra (FOUCAULT, 1978, p. 25). O primeiro, conforme reproduzido aqui em epígrafe, porque a sua autonomia é precária ou mesmo ilusória, refere-se apenas ao "pequeno paralelepípedo" que pegamos nas mãos e acomodamos numa prateleira, entre outros livros que lhe destinamos como pares - aberto e lido o livro, desconhecemos os seus limites, adentramo-nos. Sobre a segunda unidade, a obra, também não corresponde efetividade alguma, trata-se de uma função operacional, dirá Foucault mais tarde, ou de decisão seletiva de leitor ou da leitura: quais os limites da obra de Santiago? Onde e quando acaba a sua coletânea inaugural lançada há quatro décadas?

As epígrafes e as proposições de Michel Foucault introduzem as linhas que pretendo seguir nesta homenagem ao livro de 1978. Como um trabalho de desconstrução da unidade livro, unidade material e fraca, vou evocar outros livros ou outros lances críticos de Silviano Santiago que fazem eco ao primeiro, não em busca de continuidade ou de desenvolvimento no seu pensamento, mas para flagrar estratégias reincidentes em suas leituras da história cultural e da literatura brasileira ou latino-americana. O conjunto de ensaios acolhidos em Uma literatura nos trópicos, com destaque ao ensaio inicial, "O entre-lugar do discurso latino-americano", expõem a emergência de forças intempestivas, do seu trabalho contra-o-tempo, contra o seu tempo e também contra a naturalização da temporalidade como ordem de valor, uma persistente afronta à linearidade e à teleologia como um traço sucessivamente reinvestido na elaboração crítica de Santiago.

$\mathrm{Ou}$, dito a seu modo, privilegiar alguns de seus atos de desconstrução grifando os contratempos, os curtos-circuitos ou as reversões tem sido um viés meu de leitura, que prevalece na maioria das escolhas que fiz sempre que escrevi sobre Santiago. 
Com a instigação da teoria francesa já em epígrafe, o primeiro e mais conhecido ensaio da coletânea Uma literatura nos trópicos é um protótipo do gesto pós-colonial e se insurge contra o apagamento da violência civilizatória, inerente à expansão da ocidentalidade, no repertório das ciências sociais e humanas e nas histórias literárias e culturais do Brasil. Santiago expõe o incessante retorno da violência recalcada nas hierarquias entre civilização e barbárie, Europa e Novo Mundo, história colonial e historiografia nacional, hierarquias que se desdobram em outras infindáveis e assimétricas oposições, entre centro e periferia, tradição erudita e cultura popular ou massiva, estética e política. Em termos mais fiéis à sequência da argumentação e ao prognóstico do "entre-lugar", seu alvo é a polarização entre a vontade de pureza, impregnada no fundamento falocêntrico ocidental, e a vivência híbrida incontornável das sementes brotadas no Novo Mundo; entre colonização (a imposição da semelhança e da condição de cópia), e descolonização (a agressividade desviante dos simulacros).

Com a veemência própria dos anos de 1970, tempos de opressão política, agitação cultural e, com mais relevo aqui, tempo de insurreição epistemológica, as análises de Silviano Santiago descartam, por um lado, a (esperada) síntese dialética que prevalecia na alta tradição crítica brasileira daqueles anos, tanto no plano conceitual quanto no plano político, para preservar e enaltecer a coexistência de potências díspares e a fertilidade do paradoxo ou da contradição. "Apesar de dependente, universal", ensaio publicado na abertura de sua coletânea seguinte, Vale quanto pesa (1982), é, além de um título exemplar dessa reviravolta, um claro exemplo da contiguidade das páginas dos dois livros.

Por outro lado, podem ser lidos, nos ensaios de Santiago publicados em 1978, o trabalho sistemático para a reversão de classificações, a aposta no valor do híbrido, a potencialização da desordem e da transgressão e, principalmente, o valor da secundariedade:

A maior contribuição da América Latina para a cultura ocidental vem da destruição sistemática dos conceitos de 'unidade' e de 'pureza': estes dois conceitos perdem o contorno exato do seu significado, perdem seu peso esmagador, seu sinal de superioridade cultural, à medida que o trabalho de contaminação dos latino-americanos se afirma, se mostra mais eficaz. A América Latina institui 
seu lugar no mapa da civilização ocidental graças ao movimento de desvio da norma, ativo e destruidor, que transfigura os elementos feitos e imutáveis que os europeus exportavam para o Novo Mundo. (SANTIAGO, 1978, p. 9).

Em "Eça, autor de Madame Bovary", terceiro ensaio da coletânea de 1978, encontra-se, desde a desordem temporal e autoral do título, uma sucessão de deslocamentos que afetam o percurso naturalizado de um raio literário europeu, cujo centro disparador a ser rasurado corresponde à França e Gustave Flaubert, autor de Madame Bovary, e o alvo a ser reconhecido como propulsor de outro tempo está no semiperiférico Portugal e em Eça de Queirós, autor de $O$ Primo Basílio. A reflexão se desenvolve com a ajuda de uma das ficções de Jorge Luis Borges, "Pierre Menard, autor del Quijote", e em diálogo intertextual, ao mesmo tempo camuflado e acintoso, com Machado de Assis e a sua crítica a Eça de Queirós, publicada no jornal $O$ Cruzeiro um século antes, em 1878, por ocasião do lançamento do romance $O$ Primo Basílio, que integra a sua obra crítica organizada por Afrânio Coutinho (Cf. ASSIS, 1986). Essa abundância de nomes próprios e títulos nobres é deliberada, quer sinalizar a amplitude da reversão de posições instituídas e a boa corrosão dos critérios de prioridade, das noções de fonte e influência, do desprestígio da obra segunda. O recado crítico, nesse ensaio, é de paradoxal singeleza: a obra segunda e de certa forma periférica de Eça de Queirós só se torna possível - e visível - na medida em que incorpora e ao mesmo tempo rasura o romance modelar de Flaubert. $\mathrm{O}$ gesto queirosiano de admiração ao mestre e ao "romance dos romances", como Madame Bovary já foi designado, é também um lance de antropófago. Para Silviano Santiago, a ativa devoração, a "noção mal intencionada da antropofagia cultural, brilhantemente inventada por Oswald", é um dos "antídotos" para reverter a má consciência colonizada face a inevitável incorporação do que não é próprio, do que é exterior (SANTIAGO, 1982, p. 21).

$*$

Em Uma literatura nos trópicos, a noção de “entre-lugar” também emerge de um aglomerado de textos residuais e, principalmente, da justaposição de registros dos arquivos coloniais, de datas diversas, que expõem a dominação, os confrontos, a hierarquização e a violência contra corpos, línguas e culturas. 
Do capítulo dos Ensaios de Montaigne sobre os canibais do Novo Mundo (1580), o crítico destaca uma referência retórica à campanha de Pirro, rei de Éfeso, na Itália, para evidenciar, como explica, que no terceiro século antes de Cristo, como nos séculos XVI e seguintes, nos conflitos e hierarquias que são próprios do embate entre "o civilizado e o bárbaro, entre o colonialista e o colonizado, entre Grécia e Roma, entre Roma e suas províncias, entre Europa e Novo mundo" (SANTIAGO, 1978, p. 12), o menosprezo da metrópole pelo potencial de insurgência dos dominados pode ser um turning point nas relações de dominação. Outro fragmento vem de Tristes trópicos, de Lévi-Strauss, traz o vaticínio dos monges da Ordem de São Jerônimo sobre a incongruência entre indígenas de Porto Rico e a "vida humana", daí concluírem ser-lhes mais salutar "tornarem-se homens escravos do que permanecerem como animais livres" (SANTIAGO, 1978, p. 14). Santiago também resgata "informações preciosas e extraordinárias na carta escrita ao rei de Portugal por Pero Vaz de Caminha" em 1500, para, primeiro, ironizar o testemunho do escrivão de que os índios "estariam naturalmente inclinados à conversão religiosa, visto que de longe imitavam os gestos cristãos durante o santo ofício da missa" (SANTIAGO, 1978, p. 15), e em seguida para ler, na negação da fala indígena (que será retomada em diversos artigos seus posteriores, como veremos), a interdição da plurivocidade e a imposição da mímica, da cópia, do monolinguismo, do outro reduzido a espelho do europeu. Complementam o argumento e a pedagogia colonial as representações teatrais promovidas pelos jesuítas, já na segunda metade do século XVI, com textos em português e tradução em tupi-guarani, que têm o poder silenciar, a um só golpe, afirma Santiago, o código religioso, o código linguístico e o "pensamento selvagem".

Nessa sequência numerosa, embora aquém do que é trazido ao ensaio, o argumento crítico coleciona discursos que fazem a negação da contemporaneidade do Outro, do que habita um mundo designado como "novo", mas cuja novidade significa, "bizarramente" (palavra de Santiago), não pertencer ao presente, estar antes do tempo atual do europeu que conquista, antes da civilização, o primitivo, ou, na versão mais recente do neocolonialismo do século XX, está condenado a uma existência inatual, fora de moda. ${ }^{2}$

\footnotetext{
${ }^{2}$ Ou démodés, segundo Lévi-Strauss, em frase que traça, com aguda simplicidade, a equação que interessa ao crítico, a ser retomada em outros ensaios: "Les tropiques sont moins exotiques que démodés" (SANTIAGO, 1978, p. 17).
} 
É desse aglomerado anacrônico - na mais forte e fértil significação do termo, como coexistência estratégica de muitos e diversos tempos e textos culturais - que dois lances duradouros da crítica de Silviano Santiago se constituem: o valor do entre-lugar no primeiro plano, e, num segundo, a desconstrução das práticas historiográficas e comparatistas eurocentradas que então prevaleciam.

\section{Nota 1}

A primeira das minhas notas ao pé da página (e serão apenas três) recupera outros lances disruptores produzidos por Santiago ainda na década de 1970, para problematizar a Historiografia Literária, ${ }^{3}$ um recorte disciplinar de grande prestígio e repercussão em todos os níveis do sistema de ensino. Refiro-me aqui especificamente ao célebre "texto da semente" - como era designado pelos seus alunos de então, uma sequência de páginas datilografadas, sem data e sem título, ${ }^{4}$ ao que tudo indica um relato de pesquisa em andamento, que foi inserido, parcialmente, em "Uma ferroada no peito do pé: dupla leitura de Triste fim de Policarpo Quaresma", ensaio datado de 1981 e publicado um ano depois na coletânea Vale quanto pesa.

A propósito da carta de Pero Vaz de Caminha, o "texto da semente" tem uma premissa clara sobre o deslocamento ou a operação de rasura temporal que pretende:

Esclareço de início que não fui levado a ler textos portugueses e, de maneira geral, europeus, que versam sobre o Brasil e datados do século XVI e seguintes visando a uma compreensão direta da catequese, do batismo e da conversão dos indígenas, dentro de uma perspectiva teológica e europeia. ${ }^{5}$

\footnotetext{
${ }^{3}$ Para qualificar o vigor das publicações na época, vale lembrar que a História concisa da Literatura Brasileira foi publicada por Alfredo Bosi em 1970 e em 1977 havia saído De Anchieta a Euclides; breve história da literatura brasileira, do José Guilherme Merquior, dois críticos de altíssimo prestígio na década.

${ }^{4}$ Texto que foi tarefa penosa localizar vinte anos mais tarde, quando escrevi a primeira vez sobre ele - agradeço, com saudade, a Renato Cordeiro Gomes que o encontrou entre seus "papeis antigos".

${ }^{5}$ Como informado acima, a ausência de título e data impede que a citação seja referenciada como de praxe.
} 


\section{Silviano explica esse retorno pela}

[...] necessidade de reestruturar os estudos da História da Literatura entre nós, abrindo-os [...] a uma leitura onde se afirmasse a premência de se compreender o discurso literário em seus limites, ou seja, dentro/fora do discurso cultural. [...] Este gesto de leitura tinha que ser precedido de uma estratégia de descentramento, para usar a expressão de Jaques Derrida [...] que desloca, expulsa do seu lugar a cultura europeia. Deixando de ser ela, a partir de então, a cultura de referência.

Caminha, portanto, deve ser lido como um operador contra "os nossos estudos literários de caráter histórico". É útil lembrar que a "Carta” de Pero Vaz de Caminha e toda a produção textual do século XVI haviam sido expulsos dos "momentos decisivos" da história literária desde a década de 1950, pela Formação da Literatura Brasileira, de Antonio Candido (1959), exclusão confirmada por Alfredo Bosi quase vinte anos mais tarde, na sua prestigiada e então recente obra historiográfica, a História concisa da Literatura Brasileira (1970).

A historiografia literária não é, aqui, a questão mais relevante, embora sempre valha a pena destacar o persistente apagamento ou rebaixamento do discurso colonial por intérpretes consagrados da brasilidade literária e cultural; por outro lado, é relevante encontrar, nesse trabalho incipiente de Santiago, o traço incisivo da rasura temporal ou o gesto intempestivo que estou rastreando como um nó, na rede textual que ata o livro da nossa pauta a outros livros-textos do crítico.

Reativar a carta de 1500 tal como o faz Santiago é um ato de realocação ou relocação (relocation), como diriam alguns anos depois os críticos culturais e pós-coloniais, relocação temporal do Outro, contra a negação de sua contemporaneidade pela razão moderna e linear, com forte efeito hierarquizante. Os habitantes do novo mundo não cabiam no presente europeu, não podiam ser vistos como contemporâneos, embora diversos, daí a sua projeção num tempo quase imemorial, a-histórico, esvaziado da dimensão cultural; daí a tabula rasa, porém fértil, onde deverá ser lançada a semente ocidental.

Nesse breve texto, Santiago recupera, com a palavra "semente", a contiguidade etimológica que existe entre as ações de cultivar (semear) e colonizar-cultus, colere - para fazer a sua crítica da cultura histórica. Mas a ação contra o seu tempo transcende o campo disciplinar, é gesto 
político de acolhimento e reconhecimento da alteridade, contrapõe-se à autoridade euro-falo-centrada que prevalecia (ainda prevalece) no nosso campo literário e no pensamento social.

\section{Nota 2}

Em 1990, ano do centenário do nascimento de Oswald de Andrade, Santiago leu em um congresso comemorativo e logo a seguir publicou no Jornal do Brasil o "Elogio da tolerância racial",, que tem um início provocativo:

Pau-Brasil, primeira coletânea de poemas de Oswald de Andrade, serve para espicaçar os historiadores que são servos obedientes da cronologia [...]. Como um endiabrado "menino experimental", o poeta [...] resolve bagunçar o coreto do Tempo e da História ocidental. Faz ele questão de assinalar, desde o pórtico do livro, que aqueles poemas escritos em 1924 o foram "por ocasião da descoberta do Brasil". (SANTIAGO, 2006, p. 133).

Da rasura da cronologia Santiago extrai a possibilidade da reversão, na perspectiva nietzschiana recuperada por Gilles Deleuze, em outra obra de 1968 que integra as vanguardas teóricas da segunda metade do século XX, a Lógica do sentido: reverter significa tornar manifesta, fazer emergir, "encurralar" as motivações obliteradas (DELEUZE, p. 259, 1998). Ou seja, nas sequências de poemas intituladas "História do Brasil" e "Poemas da colonização" o crítico explora a recuperação e a ressignificação, pelo modernista,

[...] do que injustamente tem sido classificado 'de passado colonial brasileiro', numa visão reducionista do que é na verdade a possível contribuição cultural das raças indígenas e africanas no diálogo com a modernidade Ocidental. Esse reducionismo acaba por valorizar a razão moderna etnocêntrica, intolerante, incapaz de manter um diálogo com o seu 'outro'. [...] Esse reducionismo, em

\footnotetext{
6 "Elogio da tolerância racial" (presente em "Idéias", publicado no Jornal do Brasil em 09 de setembro de 1990), hoje publicado como "Oswald de Andrade: elogio da tolerância racial" em Ora direis puxar conversa (2006).
} 
geral, rechaça o saber antropológico, pois desqualifica como equívoco ufanista qualquer contribuição que possa advir daquele conhecimento. (SANTIAGO, 2006, p. 137).

Santiago designa como "reducionismo" a centralidade da razão europeia na configuração da verdade histórica e elenca, no artigo, a sua evidência em obras consagradas que ajudam o leitor a compreender, de modo diferencial, que contraria o senso histórico hegemônico, as implicações do apagamento da alteridade no plano do simbólico e no imaginário social. O primeiro deles, em "Notícia da atual literatura brasileira: instinto de nacionalidade", publicado por Machado de Assis em 1873, onde se afirma que "a civilização brasileira não está ligada ao elemento indiano, nem dele recebeu influxo algum; e isto basta para não ir buscar entre as tribos vencidas os títulos da nossa personalidade literária" (SANTIAGO, 2006, p. 138). Neste caso, o título e o subtítulo do artigo pautam o âmbito de sua duradoura repercussão: a exclusão das populações autóctones - em contínuo e sempre renovado processo de extermínio tanto na historiografia quanto na atualização do imaginário em fins do século XIX. O segundo exemplo de reducionismo, oito décadas depois, faz eco ao vaticínio de Machado de Assis, agravando-o nos termos e na contingência cultural da dita fase heroica do modernismo brasileiro. Tratase da conferência proferida por Graça Aranha na Academia Brasileira de Letras, em 1924, na qual o porta-voz da renovação estética e organizador da Semana de Arte Moderna de dois anos antes postula, a propósito do "espírito novo":

O nosso privilégio de não termos o passado de civilizações aborígenes facilitará a liberdade criadora. Não precisamos, como o México e o Peru, remontar aos antepassados Maias, Astecas ou Incas, para buscar nos indígenas a espiritualidade nacional. O Brasil não recebeu nenhuma herança estética dos seus primitivos habitantes, míseros selvagens rudimentares. Toda a cultura nos veio dos fundadores europeus (Graça Aranha apud SANTIAGO, 2006, p. 138, grifo meu). ${ }^{7}$

\footnotetext{
${ }^{7}$ A citação feita no ensaio foi aqui ampliada com a frase seguinte proferida por Graça Aranha, sobremodo esclarecedora e não reproduzida por Santiago: "Toda a cultura nos veio dos fundadores europeus" (a conferência integral está em Guardados da Memória, publicação da Academia Brasileira de Letras, disponível em http://www.academia.org. br/abl/media/RB\%2057-GUARDADOS\%20DA\%20MEMORIA.pdf
} 
Em Formação do Brasil contemporâneo (1942), Santiago aponta o seu terceiro exemplo de "reducionismo" e o etnocentrismo contidos no diagnóstico de Caio Prado Júnior acerca do "nível cultural ínfimo dos índios e negros", e ao vaticiná-los como "fermento corruptor da outra cultura, a do senhor branco que the sobrepõe" (SANTIAGO, 2006, p. 140).

É contrastante a última referência do "reducionismo" que compõe o argumento de Santiago, embora siga uma estratégia assídua em seus escritos, como vimos na construção exemplar do primeiro ensaio de Uma literatura nos trópicos: a expansão horizontal e dispersiva do argumento, com a coleta de fragmentos díspares, de discursos temporalmente desordenados, que são apresentados ao leitor como uma colagem a exibir sempre uma outra coisa, diversa, que tumultua paisagens discursivas e hierarquias estabelecidas. O último exemplo de "reducionismo" foi capturado no discurso proferido pelo filósofo Jürgen Habermas em 1980, quando recebeu o prêmio Theodor W. Adorno, intitulado "Modernidade versus Pós-modernidade". Ao se referir às vanguardas históricas europeias do início do século XX como exemplo das aporias que vitimaram o projeto civilizacional e cultural moderno, Habermas expõe, segundo Santiago, a marca eurocêntrica e a intolerância da razão histórica com o Outro, ao se posicionar contrário à emergente valorização dos objetos de arte africanos que então inundaram a Europa e inspiraram as figurações cubistas, provavelmente mais do que qualquer geometria. A propósito dessa rasura na racionalidade representacional, escreveu nostalgicamente Habermas e Santiago transcreve: "Substitui[u]-se a memória histórica pela afinidade heroica do presente com os extremos da história: um sentido do tempo no qual a decadência se reconhece de imediato no bárbaro, no selvagem e no primitivo" (SANTIAGO, 2006, p. 142).

Embora à primeira vista Habermas seja um intruso no elenco de evidências recolhidas no acervo brasileiro, no artigo de Santiago prevalece o vigor do anacronismo: a Habermas quem responde é Oswald de Andrade e o Matriarcado de Pindorama.

\section{Nota 3}

Em 2000, como parte das comemorações dos 500 anos do Descobrimento do Brasil, foi publicada pela Editora Nova Aguillar, com o patrocínio do Ministério da Cultura e do Itamaraty, a coleção Intérpretes do Brasil, coordenada por Silviano Santiago, reunindo onze 
destacados autores do pensamento social brasileiro. ${ }^{8} \mathrm{Na}$ Introdução aos três volumes, o crítico afirma:

Os muitos livros que temos e que envolvem, de maneira descritiva, ensaística ou ficcional o território chamado Brasil e o povo chamado brasileiro, sempre serviram a nós de farol [...]. Com sua ajuda e facho de luz é que temos caminhado, pois eles iluminam não só a vasta e multifacetada região em que vivemos, como também a nós, habitantes dela que somos.

A Introdução à coletânea, entretanto, faz o movimento controverso e intempestivo, reincidente, que estamos rastreando na composição crítica de Silviano Santiago. O organizador transfere a terceiros o comentário crítico de cada uma das obras escritas entre 1883 ( $O$ abolicionismo, de Nabuco) e 1975 (A revolução burguesa no Brasil, de Florestan Fernandes), os "livros farol", que partilham tanto o impulso escrutinador e modernizador do país quanto o contínuo trabalho de assegurar a estabilidade da hierarquia social e da liderança político-econômica que dão forma à nação.

Santiago os pretere para se dedicar a uma cuidadosa genealogia do silenciamento do outro e das violências que instituem a hierarquia racial, a desigualdade social e as distâncias culturais olhando, pode-se assim dizer, por um "espelho retrovisor". ${ }^{9}$ A introdução aos Intérpretes faz uma leitura suplementar - e concorrente - do país, em fricção com

${ }^{8}$ Joaquim Nabuco (O abolicionismo, 1863), Euclides da Cunha (Os Sertões, 1902) Manuel Bonfim (América Latina, 1905), Oliveira Viana (Populações meridionais do Brasil, 1920), Alcântara Machado (Vida e morte do bandeirante, 1943), Paulo Prado (Retrato do Brasil, 1928), Gilberto Freyre (Casa-grande \& Senzala, 1933; Sobrados e mocambos, 1936; e Ordem e Progresso, 1957, reunidos em Introdução à História Patriarcal do Brasil), Sérgio Buarque de Holanda (Raizes do Brasil, 1936), Caio Prado Júnior (Formação do Brasil contemporâneo, 1942), Florestan Fernandes (A revolução burguesa no Brasil, 1975), Graciliano Ramos (Vidas secas, 1938).

${ }^{9}$ No ensaio "Vale quanto pesa" (SANTIAGO, 1982), uma das muitas apreciações do modernismo brasileiro feitas por Silviano Santiago, pode-se ler a dissonância que produziu na sua fortuna crítica, ao destacar o relevo do discurso memorialista e problematizar o clamor geral da ruptura e da inovação. É desse artigo a imagem do "espelho retrovisor" como lugar de elaboração crítica, imagem ressignificada por mim como operador textual no ensaio em que avalio a sua "interpretação dos intérpretes" (CUNHA, 2011). 
a grande tradição do pensamento social brasileiro reunido na coletânea. Inicia com mais um retorno ${ }^{10}$ à Carta de Pero Vaz de Caminha para ler, desta vez, como na constatação da ausência de liderança entre os índios ou na afirmação do espaço vazio de um chefe dá-se, na configuração do país, a fixação discursiva e a concentração de toda liderança "nas mãos brancas (ou mestiças) que se expressavam [...] em língua portuguesa, a companheira do império" (SANTIAGO, 2000, p. XXII). Em Cultura e opulência do Brasil (1711), de André João Antonil, retoma a imagem plasmada do corpo colonial, esdrúxula, mas incontornavelmente familiar a todos os brasileiros: cabeça e corpo equivalem ao senhor, proprietário e explorador do trabalho servil, e aos homens livres, leia-se o colono; do corpo branco e senhorial saem os braços (os feitores) e os pés e mãos, os escravos. Importa principalmente, à estratégia crítica insurgente de Santiago, o comentário posterior de Antonil: "os escravos são as mãos e os pés do senhor de engenho porque sem eles no Brasil não é possível fazer, conservar e aumentar fazenda nem ter engenho corrente" (SANTIAGO, 2000, p. XXVI). N'O Guarani (1857), de José de Alencar, Santiago lê, por um lado, o adensamento e a legitimação da liderança senhorial que funda o discurso da jovem nação, com a entronização, no corpo do fidalgo, do poder do Rei; por outro, nos embates do enredo do herói e seus coadjuvantes indígenas contra os aventureiros, aponta a hierarquização rígida da sociedade e da comunidade imaginada necessária à figuração da nacionalidade. Em paralelo, destaca Santiago, e não só em Alencar, fazse ali o total apagamento dos africanos e seus descendentes, a completa obliteração da "mancha negra" e da escravidão.

No capítulo de Memórias Póstumas de Brás Cubas (1881), intitulado "Um episódio de 1814", na emblemática imagem do país fixada pelo afro-brasileiro Machado de Assis - o menino branco chicoteando o moleque negro, dobrado de quatro pés sobre o chão liso da sala -, Santiago, no seu espelho retrovisor, intempestivo e quase a contrapelo, expõe a articulação indelével entre a construção da liderança, da hierarquia, da ordem social e o racismo correlato do escravismo.

${ }^{10}$ Cf. "Curto circuito, leituras de Silviano Santiago" (CUNHA, 1997), em que fiz um mapeamento da Carta de Pero Vaz de Caminha nos ensaios de Santiago, considerando textos publicados até 1990. Depois da Introdução aos Intérpretes do Brasil, reencontraremos o destaque dado por Santiago a esse texto fundador em Raízes e Labirinto da América Latina (2006). 
O diferencial nessa sua interpretação do Brasil, construída com uma montagem inusitadamente cronológica e ordenada, está no deslocamento da operação sempre tida como prioritária na invenção cultural da nação. Em vez da ênfase nas versões discursivas da unidade, da agregação conciliadora e do pertencimento, investe na apreciação "da máquina textual de diferenciação, cujo norte é a nossa origem europeia" (SANTIAGO, 2000, p. xxix), para ler nela a força motriz da separação, da exclusão, da desigualdade.

Procurei desenhar aqui uma rede de ensaios e artigos na qual a coletânea de 1978 é um nó, tendo como fio condutor o contínuo trabalho de rasura, intempestivo e extemporâneo empreendido por Santiago para a perlaboração do arquivo colonial e de seu desdobramento na ordem nacional.

Pode-se considerar que a "perlaboração histórico-cultural", que foi reivindicada por Adorno, para que a Alemanha fizesse o trabalho de "lembrar para esquecer" o holocausto, o trabalho de "perlaboração psíquica", tal como proposto por Freud, que implica uma travessia, o passar por dentro do registro traumático, e o trabalho de "perlaboração da memória colonial" podem se entrelaçar no ambivalente movimento que está implicado na partícula pós, como retorno, releitura e desconstrução, ressignificação, recriação do passado. Avant la lettre, o gesto pós-colonial de Silviano Santiago sublinha a importância da coisa descrita como pós, a colonialidade recalcada pela tradição historiográfica e no segmento mais prestigiado do pensamento social brasileiros. Sendo assim, na perspectiva pós-colonial reivindicada pelo próprio crítico em sua entrevista mais recente, publicada na página da Biblioteca Virtual do Pensamento Social (BVPS), não pode ser resumida como engajamento em uma vertente crítica. É, acima de tudo, uma posição inevitável diante do presente.

Na entrevista, aliás, Santiago faz uma instigante provocação para outras notas de pé de página, ao trazer dois ensaios mais remotos, outros lances da travessia perlaboladora e da montagem intempestiva, outros nós que poderemos acrescentar à rede que desenhamos aqui.

Destaco [...] o ensaio "A palavra de Deus", publicado na revista Barroco em 1971, e o ensaio "Iracema: alegoria e palavra", de 1963, que não consta de Uma literatura nos trópicos por sugestão de colega. Em "A palavra de Deus”, busco analisar como o código linguístico (a língua portuguesa) se associa ao código religioso (a catequese 
cristã) para entender do ponto de vista pós-colonial o texto inaugural da nossa cultura. Em "Iracema", interesso-me, entre outras questões, pela criação de palavras em tupiguarani, aproximando-a das propostas joycianas então divulgadas pelos poetas concretos (SANTIAGO, 2018).

Em artigo publicado no Suplemento Pernambuco em maio de $2018^{11}$ escrevi, a propósito da atualidade do livro de 1978: "Com sua sagacidade intempestiva ou por seu rico anacronismo, Uma literatura nos trópicos pode sustentar uma contundente interpelação a nosso tempo." Esta interpelação continua em curso, nos escritos e nas entrevistas de Santiago.

\section{Referências}

ASSIS, Machado. Crítica. In: COUTINHO, Afrânio (org.). Obra completa de Machado de Assis. Rio de Janeiro: Nova Aguilar, 1986. v. 3, p. 903-913.

BOSI, Alfredo. História concisa da literatura Brasileira. São Paulo: Cultrix, 1970.

CANDIDO, Antonio. Formação da Literatura Brasileira: momentos decisivos. São Paulo: Martins, 1959. 2 v.

CUNHA, Eneida Leal. Curto circuito, leituras de Silviano Santiago. Cadernos do Centro de Pesquisas Literárias da PUC-RS, São Paulo, v. 3, n. 1, p. 135-142, abr. 1997.

CUNHA, Eneida Leal. Do crânio da onça jabuti faz seu escudo: Silviano Santiago como intérprete do Brasil. Letterature d'America, Roma, a. XXI, n. 135 , p. 67-79, 2011.

CUNHA, Eneida Leal. Escrever contra, a urgente tarefa deste milênio. Suplemento Pernambuco, Recife, n. 147, p. 16-17, maio 2018.

DELEUZE, Gilles. Lógica do sentido. Tradução de Luiz Roberto Salinas Fortes. São Paulo: Perspectiva, 1998.

FOUCAULT, Michel. A arqueologia do saber. Tradução de Luiz Felipe Baeta Neves. Rio de Janeiro: Forense Universitária, 1978.

${ }^{11}$ Cf. CUNHA, 2018. 
SANTIAGO, Silviano. Intérpretes do Brasil. Rio de Janeiro: Nova Aguilar, 2000. $3 \mathrm{v}$.

SANTIAGO, Silviano. Ora direis puxar conversa. Belo Horizonte: Editora UFMG, 2006.

SANTIAGO, Silviano. Ruptura e tradição: Uma literatura nos trópicos 40 anos. Entrevista concedida a Andre Bittencourt e Maurício Hoelz. Blog BVPS, [S. l.], 09 set. 2018. Disponível em: https://blogbvps.wordpress. com/2018/09/09/ruptura-e-tradicao-uma-literatura-nos-tropicos-40-anosentrevista-com-silviano-santiago/. Acesso em: 20 out. 2018.

SANTIAGO, Silviano. Uma literatura nos trópicos: ensaios sobre dependência cultural. São Paulo: Perspectiva: Secretaria da Cultura, Ciência e Tecnologia do Estado de São Paulo, 1978.

SANTIAGO, Silviano. Vale quanto pesa: ensaios sobre questões políticoculturais. Rio de Janeiro: Paz e Terra, 1982.

Recebido em: $1^{\circ}$ de outubro de 2019. Aprovado em: 6 de fevereiro de 2020. 